\section{Horticultural Science in France}

M. Georges Truffaut lectured to the Royal Horticultural Society in October of last year, on the experiments on manuring, pest control and microbiology of the soil, which have been carried out under his direction at Versailles. The text of this lecture appears in the Society's Journal (62, Pt. 3, March) and portrays results which are in sufficient accord with the findings of research institutes in Great Britain to warrant thankfulness, and yet are original enough to provide great stimulation. $\mathbf{M}$. Truffaut and his colleagues have shown that only when the nitrogen, phosphoric acid and potash are combined upon a basis of their atomic weights will the soil yield its fullest increase in response to artificial manures. The insistence of the earlier agricultural chemists on the necessity of lime for the growth of most crops is countered vigorously by the workers at Versailles, who find that the presence of calcium ions is often undesirable in garden soil. The most welcome contribution of the lecture to the science of pest control is perhaps the description of a new spray fluid known as 'Elgetol'. This is a mixture of a synthetic yellow dye with wetting agents. It has a milder action upon the tree than lime sulphur or tar oil winter wash, but it is quite effective against the overwintering eggs of various insect pests. Workers at the Versailles laboratories have established the fact that soil bacteria can obtain their energy exclusively from carbohydrates and organic salts excreted by the root-hairs of plants. "Living green plants are thus the main source of energy for soil micro-organisms." The lecture also reviewed a wider field of work than the results here mentioned; the sections on calcium metabolism and the control of pests during winter are most informative.

\section{The Post Office and Broadcasting}

Is the Journal of the Institution of Civil Engineers of March, a report is given of the interesting discussion of a recent paper by Sir Noel Ashbridge on broadcasting. Sir George Lee pointed out that the Post Office acts in several ways as an auxiliary to broadcasting. An important function which it fulfils is reducing the interference which many listeners experience on their wireless sets from electrical machinery. Last year, it investigated 40,000 cases of interference. The total circuit mileage used by the B.B.C. in the P.O. network last year was about 6,000. A large number is also in use for Continental broadcasts. Every country in Europe has now these special circuits, and they are often used for the broadcasting of special events. It is estimated that if 80 per cent of the mains-operated receivers were in use during some important event, such as the coronation, when most people switched on their receivers, the load on the grid system due to this cause alone would be 250,000 kilowatts. The annual consumption of receivers is about 270 million units, quite an appreciable fraction of the load on the grid. Another interesting statistical fact which Sir George Lee gave was in connexion with the three short-wave and one long-wave station which work to America every day. Several hundred kilowatts are radiated from Great Britain towards America but all the power picked up in America would be only sufficient to raise a fly seven inches high in one year. On land-lines, amplifiers are put in at about every fifty miles and there is therefore a large number of amplifying stations between Great Britain and San Francisco. Each amplifier receives such feeble signals that they are just distinguishable from the inherent noise in the circuit, and it amplifies them only sufficiently for the signals to be received at the next station; yet the total amplification received in that repeated process is $10^{256}$, a number inconceivably great !

\section{Electric Locomotives for the Natal Railways}

From the Metropolitan-Vickers Electrical Company's Gazette of March 1937, we learn that during the year 1935 it had received orders for twenty-five new 1,200 h.p. electric locomotives for the railways of Natal from the South African Government. The new locomotives had become necessary because of the increased traffic and the doubling of the route mileage. The company had already supplied ninetyfive locomotives which had been in constant service in Natal for terms varying from nine to twelve and a half years. The line from Glencoe to Pietermaritzburg is very hilly. Glencoe is situated near the centre of the Natal coal-field, and the transport of coal to Durban constitutes a large part of the traffic on the line. Power is supplied from Colenso through a three-phase 88,000 volt transmission system. The new locomotives differ from the original ninety-five in many details, but they are suitable for multiple unit working in combination with any of the ninety. five original locomotives. Each locomotive is of 1,200 h.p. capacity with four axles each driven by a 300 h.p. traction motor. The auxiliary machines in each locomotive consist of an air compressor, an exhauster and two motor generators of $16 \mathrm{~kW}$. and $28 \mathrm{~kW}$. capacity respectively. The compressor supplies compressed air for the operation of the locomotive brakes. The exhauster produces the vacuum for the train brakes. Of the many improvements embodied in the new locomotives the most important are in the control gear and the pantagraphs for collecting the current. The latter work with a line pressure of $16 \mathrm{lb}$. as against the original $26 \mathrm{lb}$. and weigh about $400 \mathrm{lb}$. less. They can now be raised to the collecting wire without mechanical shock, and similarly there is no shock when lowered to the roof.

\section{Recent Solar Activity and Auroras}

A Note received from M.M. Eigenson and Gnevishev of the Pulkovo Observatory directs attention to the high degree of sunspot activity on and about January 31 last (when the Tashkent Observatory recorded a total spotted area of 4000 millionths of the sun's hemisphere) and a series of auroras which were extensively observed from the U.S.S.R. between January 31 and February 3. The solar activity and associated terrestrial phenomena (including the 